\title{
STS Markers for Comparative Mapping in Legumes
}

\author{
S. Brauner \\ Department of Biology, Ashland University, Ashland, $\mathrm{OH} 44805$ \\ R.L. Murphy and J.G. Walling \\ Department of Plant Sciences and Plant Pathology, Montana State University, Bozeman, MT 59717
}

J. Przyborowski

Department of Plant Breeding and Seed Production, University of Warmia \&Mazury in Olsztyn, 10-724

Olsztyn-Kortowo, Poland

N.F. Weeden ${ }^{1}$

Department of Plant Sciences and Plant Pathology, Montana State University, Bozeman, MT 59717

\begin{abstract}
Additional Index words. pea, Pisum sativum, lentil, Lens culinaris, CAPS, linkage map
Abstract. DNA primers for 37 genes have been developed in pea (Pisum sativum L.). Two-thirds of these primers also amplify orthologous sequences in lentil (Lens culinaris). The primers were designed to be complementary to highly conserved sequences in exons of known genes. In addition, most of the priming sequences were selected to be 1000 to 3000 bp distant on the genomic DNA and to amplify a fragment that contained at least one intron. Segregating sequence polymorphism in mapping populations of recombinant inbred lines (RILs) derived from wide crosses in Pisum was observed by restriction of the amplified fragment with endonucleases recognizing four-base restriction sites. Successful mapping of 36 of these genes in pea demonstrated the utility of these primers for mapping, and it appears likely that the primers should have general utility for comparative mapping in legumes.
\end{abstract}

The location of genes on a linkage map is a process in which each new locus provides another tool for future studies. The development of DNA technologies has created a nearly limitless supply of molecular markers available in all plant species. Hence, the linkage maps for many plant species have gradually been developed to become powerful tools for genetic studies and crop improvement. In pea, a consensus linkage map with over 1000 markers has been assembled (Weeden et al., 1998). Over 800 of the markers on this map were polymorphic in the population of recombinant inbred lines (RILs) used to establish this map, providing a level of saturation greater than one marker per centiMorgan. Additional linkage maps have been developed for other pea crosses (Dirlewanger et al., 1994; Ellis et al., 1992; Gilpin et al., 1997; Irzykowska et al., 2001; Laucou et al., 1998; McCallum et al., 1997), making available literally thousands of DNA markers in pea.

Unfortunately the majority of these markers have limited utility for comparative mapping studies. Although the various pea maps can be compared with each other through a number of common anchor loci, most of the markers mapped in various crosses are RAPD markers or other markers that are difficult to transport between pea crosses. Furthermore, such markers can rarely be transferred to detect orthologi in crosses of related legume species such as lentil (Lens culinaris Medik.) or chickpea (Cicer arientinum L.). For such comparative mapping applications, conserved DNA sequences such as those found in the exons of many genes, appear to hold the greatest promise. Restriction fragment length polymorphism (RFLP) mapping of cDNA clones has traditionally provided good anchor markers, but the requirement for large amounts of DNA and the general involvement of radioisotopes complicates the routine application of this tech-

Received for publication 7 Feb. 2002. Accepted 8 Apr. 2002 We are indebted to Charlie Brummer and John Foster for their thorough reading of a previous draft of this manuscript. S. Brauner was supported by a senior study leave from Ashland Univ. This manuscript is journal article number 2002-17 of the Montana Agricultural Experiment Station.

${ }^{1}$ Corresponding author; e-mail nweeden@montana.edu. nique. With many DNA sequences now available in GenBank and other databases, DNA primers can be designed to specifically amplify a portion of a previously sequenced gene by means of the polymerase chain reaction (PCR), producing a sequence tagged site (STS) (Olsen et al., 1989). This approach may be more efficient for developing and identifying anchor markers. A convenient method for detecting STS marker sequence polymorphism is through the use of restriction endonucleases, to produce cleaved amplified polymorphic sequence or CAPS markers (Jarvis et al., 1994).

The CAPS approach has been used to locate genes in pea and other crops. Gilpin et al. (1997) designed primers to sequenced cDNAs obtained from etiolated pea seedlings and mapped a number of CAPS loci on the consensus map or linkage maps developed in other crosses. Schneider et al. (1999) obtained gene sequences from GenBank to develop gene specific primers for mapping in Beta vulgaris, again primarily by means of CAPS analysis. In these cases, the size of the PCR product was usually under $1000 \mathrm{bp}$ and required a high degree of genetic diversity in the germplasm (or between the two parents) in order to obtain a polymorphism within the PCR product. Such an approach was most effective for wide crosses or for PCR fragments that contained rapidly evolving sequences. Both of these studies demonstrated that amplified products containing introns were more polymorphic than those containing only coding sequences.

We are interested in comparative mapping in the family Fabaceae and in the development of STS markers that potentially can be applied across different genera. Boutin et al. (1995) demonstrated that considerable conserved synteny existed between the linkage maps of Phaseolus and Vigna species and that some gene-order conservation also existed between the genera Glycine and Phaseolus. Additional synteny among legume genomes has been suggested by map comparisons between these genera and Arabidopsis (Lee et al., 2001) and Medicago (D.J. Kim, personal communication). Within the cool season legumes Weeden et al. (1992) estimated that at least $40 \%$ of known genes show syntenic locations between pea and lentil, and Simon and 
Table 1. Primer Sequences and origin of primer design.

\begin{tabular}{|c|c|c|c|c|}
\hline Gene & Symbol & $\begin{array}{l}\text { GenBank } \\
\text { accession no. }\end{array}$ & Primer & $\begin{array}{l}\text { Primer } \\
\text { sequence }\end{array}$ \\
\hline \multirow[t]{2}{*}{ Acetohydroxy acid isomeroreductase } & Aair & AJ251333 & $\mathrm{F}$ & 5' CACACATCCCGTTTCGCTC \\
\hline & & & $\mathrm{R}$ & 5' GAATGCCССТTCTTCСТCAAG \\
\hline Actin & & & $\mathrm{R}$ & 5' TTCCTGTGTACTATTGATGG \\
\hline \multirow[t]{2}{*}{ Ascorbate peroxidase } & Apxl & M93051 & $\mathrm{F}$ & 5' ATCGCTGAGAAGAAATGC \\
\hline & & & $\mathrm{R}$ & 5' CAAGAGGGCGGAATACAG \\
\hline Apyrase S-type & & & $\mathrm{R}$ & 5' CAAAATACATCAATCGCTCA \\
\hline \multirow[t]{2}{*}{ Beta-fructosefuranosidase } & bfruct & X85328 & $\mathrm{F}$ & 5' ATCACTTTCAACCTCTCAAGAA \\
\hline & & & $R$ & 5' TTCCCCATACAGCACCTTTAG \\
\hline \multirow[t]{2}{*}{ Protochlorophyllide reductase } & CipPor & X63060 & $\mathrm{F}$ & 5' ACTGCTAAGGCTTTGGCTGA \\
\hline & & & $\mathrm{R}$ & 5' AGATTTTGTTAGGCTTGGATCACT \\
\hline Constitutively photomorphogenic protein & Copl & AJ276592 & $\mathrm{F}$ & 5' CGAACTTCCTGCTCGATAAG \\
\hline Diminuto & & & $\mathrm{R}$ & 5' TCAAAGCCTGCTTCTGGGTA \\
\hline \multirow[t]{2}{*}{ Disease resistance response protein } & DRR49 & U31669 & $\mathrm{F}$ & 5' ATGGGTGTTTTTAATGTTG \\
\hline & & & $\mathrm{R}$ & 5' AGTTGTAATCAGGATGAG \\
\hline \multirow[t]{2}{*}{ Fructose bisphosphatase ${ }^{y}$} & Fbpase & L34806 & $\mathrm{F}$ & 5' ССТTACTCTCСТTCACGTCT \\
\hline & & & $\mathrm{R}$ & 5' СТTТTСААССТТСТССАССТ \\
\hline \multirow[t]{2}{*}{ Farnesyltransferase } & Ftase & L08664 & $\mathrm{F}$ & 5' GGTGGATATGCTGGGGGA \\
\hline & & & $\mathrm{R}$ & 5' AGAATATATTGCTGTAAGGC \\
\hline \multirow[t]{2}{*}{$\mathrm{T}$ protein of glycine decarboxylase complex } & $g d c T$ & AJ222771 & $\mathrm{F}$ & 5' AGATGGTTCCTTTTGCTGGT \\
\hline & & & $\mathrm{R}$ & 5' АТСТСАААТССАТСТТСАСС \\
\hline \multirow[t]{2}{*}{ Gibberellin 2 beta-hydroxylase } & $G i b 2 B H$ & AF101383 & $\mathrm{F}$ & 5' TCTCСТCACAACCAATCAAGA \\
\hline & & & $\mathrm{R}$ & 5' CAAGCCTATTATCAGCCAACC \\
\hline Heat shock transcription factor & $h s f A$ & AJ010644 & $\mathrm{F}$ & 5' CTTCGTTCGTCAACTCAACACC \\
\hline & & & $\mathrm{R}$ & 5' AAAAACCCTTCATTCGCAAAT \\
\hline Isovaleryl-CoA dehydrogenase & $i v d h$ & AJ010946 & $\mathrm{F}$ & 5' CACTTCCTTCСТCTTTGACGAC \\
\hline & & & $\mathrm{R}$ & 5' AACCTGCGTTGCTCTTTCAG \\
\hline Leghemoglobin & $L b$ & AB009844 & $\mathrm{F}$ & 5' CTTTAGTKAATAGCTCATGGG \\
\hline & & & $\mathrm{R}$ & 5' AGCAAAGCTTCTTTAACCAC \\
\hline Superoxide dimutase $^{\mathrm{u}}$ & Sodmt & M63003 & $\mathrm{F}$ & 5' GAACATGCCTACTACTTACAG \\
\hline & & & $\mathrm{R}$ & 5' СТСТСТTТСТСАТАТАСТTСАС \\
\hline Abscisic acid induced protein HVA 22 & P393 & Gilpin et al. & $\mathrm{F}$ & 5' CTGGTTGGTCCTTCCTT \\
\hline & & & $\mathrm{R}$ & 5' AAAGAGTGACAAGAACC \\
\hline Glyceraldehyde 3-phosphate dehydrogenase & P628 & Gilpin et al. & $\mathrm{F}$ & 5' ATGTGGTCTCAACTGAC \\
\hline & & & $\mathrm{R}$ & 5' AGCTATTGCAAACATGAC \\
\hline Phenylalanine ammonia lyase & Paal1,2 & D10002 & $\mathrm{F}$ & 5' TGGAAACAGTAGCAGCAGCC \\
\hline & & & $\mathrm{R}$ & 5' AAGAAATTGGAAGAGGAGCA \\
\hline Phosphenolpyruvate carboxylase & Pepcn & D64037 & $\mathrm{F}$ & 5' GCAAAAGTGAGTGAAGATG \\
\hline & & & $\mathrm{R}$ & 5' GCTTGGAAAACATTAAGGGTTG \\
\hline Phytochrome apoprotein & phy & X14077 & $\mathrm{F}$ & 5' CCTATTTTGGCAGTGGATGTTG \\
\hline & & & $\mathrm{R}$ & 5' ACTTCCGACTGATGTGTAGGCT \\
\hline ADP-glucose pyrophosphorylase & $R b$ & X96766 & $\mathrm{F}$ & 5' ATGGCTTCTGGTTGTGTGAGCTTG \\
\hline & & & $\mathrm{R}$ & 5' TGCAGTTTCAAGGGAGAGGATATAG \\
\hline Pectin methylesterase ${ }^{\mathrm{x}}$ & rcpmel & AF081457 & $\mathrm{F}$ & 5' GTTCAAAACTGTGGCTGAGGCT \\
\hline & & & $\mathrm{R}$ & 5' GTGTTCTGGTTTGGGTCTTCTC \\
\hline
\end{tabular}


Muehlbauer (1997) reported a similar percentage of synteny when comparing the genetic maps of lentil and chickpea.

The availability of complete sequences for many pea genes in GenBank has made it possible to design primers amplifying larger sequences that specifically include one or more introns, thus increasing the likelihood of detecting polymorphisms. Primer design to highly conserved regions in coding sequences also increases the likelihood that the same primers will function for comparative mapping. Such an approach was used by Brunel et al. (1999) to amplify orthologous sequences between Arabidopsis thaliana and Brassica napus in order to observe polymorphism in the size of the amplified fragment. Here we present primer sequences for 36 pea genes that amplify relatively long $(>500 \mathrm{bp})$ PCR fragments. The fragments display polymorphism when digested with four-base recognition site endonucleases. These genes were successfully located on the pea linkage map using the revealed polymorphism.

\section{Material and Methods}

Primer sequences were generally obtained from gene sequences available in the GenBank database (http://www. ncbi.nlm.nih.gov/). Exceptions include two cDNA sequence (P393 and P628) reported by Gilpin et al. (1997). In general, we used a pea sequence as the basis for primer design, but determined the conserved nature of this sequence by comparison of the entire gene sequence with the equivalent gene in soybean (or some other legume) and in Arabidopsis. In most cases the size of the PCR fragment expected in pea could be predicted from the corresponding sequences, as well as the number and size of the introns. We attempted to choose priming sites that would generate a fragment at least $1200 \mathrm{bp}$ long and to span more than one intron. In certain cases (bfruct, DRR49, Gsp, Hop 1, hsfA, rcpme 1 and Rpl22) the size of the gene or arrangement of introns precluded the amplification of a fragment $>1000 \mathrm{bp}$. In several cases we were able to design primers that gave much larger PCR fragments. Most of the primers were designed by importing exon sequences from
GenBank into Primerfinder v.0.07 (http://eatworms.swmed.edu/ $\sim$ tim/primerfinder/) and searching for primers that were generally 18 to $22 \mathrm{bp}$ long with annealing temperatures of 55 to $65^{\circ} \mathrm{C}$ and minimal self-dimerization and hairpin properties. Exons that were revealed in BLAST searches to show considerable homology among legume genera were preferentially used for primer design when primers with suitable physical properties could be developed for them.

DNA was extracted from young leaves by a standard CTAB miniprep isolation procedure (Torres et al., 1993), and $1 \mathrm{~mL}$ of the isolated DNA was used as template for PCR. PCR was performed in $25 \mu \mathrm{L}$ reactions containing $3 \mathrm{~mm} \mathrm{MgCl}_{2}, 0.25 \mathrm{~mm}$ each dNTP and $0.8 \mathrm{~mm}$ each of the forward and reverse primers. For fragments with an expected product size $<2000 \mathrm{bp}, 0.5$ units of Taq polymerase (Promega) were used. For longer fragments, 0.05 units of Accutaq LA (Sigma) was used as the thermostable polymerase. The amplification parameters were $94{ }^{\circ} \mathrm{C}$ for $2 \mathrm{~min}$ for the initial denaturation followed by 35 cycles of $30 \mathrm{~s}$ at $94^{\circ}$, $2 \mathrm{~min}$. at the annealing temperature appropriate for the primer pair, and $2 \mathrm{~min}$ extension at $72{ }^{\circ} \mathrm{C}$. The final extension was performed for $8 \mathrm{~min}$ at $72{ }^{\circ} \mathrm{C}$. For longer fragments the extension time in each cycle was increased by 60 s for every 1000 bp $>2000$ bp. The amplifications were performed in either an MJ PTC-100 or MJ DNA Engine thermal cycler. Annealing temperatures for primer pairs were optimized individually by testing over a range of temperatures, and for some amplicons for which the expected product sizes were $>2500 \mathrm{bp}$, other parameters were changed to achieve consistent amplification. Five microliters of reaction products was subjected to electrophoresis on a $1 \%(\mathrm{w} / \mathrm{v})$ agarose gel in $1 \times$ TBE buffer to test for successful amplification, and 5 to $10 \mu \mathrm{L}$ of the remaining PCR product was then digested in $25 \mu \mathrm{L}$ reactions with restriction endonucleases with four-base recognition sequences to test for polymorphism among the parental lines. The restriction digestions used the buffer provided with each enzyme.

Two populations of recombinant inbred lines (RILs) were used to map the amplified sequences. The JI1794 x Slow $\mathrm{F}_{2}$ -

Table 1. Continued.

\begin{tabular}{|c|c|c|c|c|}
\hline Gene & Symbol & $\begin{array}{l}\text { GenBank } \\
\text { accession no. }\end{array}$ & Primer & $\begin{array}{l}\text { Primer } \\
\text { sequence }\end{array}$ \\
\hline \multirow{2}{*}{ Ribosomal protein 22} & Rpl22 & M60951 & $\mathrm{F}$ & 5' CTCTCTCTTTAGCCATTAAC \\
\hline & & & $\mathrm{R}$ & 5' CTTCCTTGTCAGACTCATC \\
\hline S-adenosyl-L-homocysteine hydrolase & & & $\mathrm{R}$ & 5' AAGAGCAGCAACCTTCTCATCAA \\
\hline \multirow[t]{2}{*}{ Sucrose synthase } & Ssyn & AJ001071 & $\mathrm{F}$ & 5' GGGAAAGGGATTTTGCAAC \\
\hline & & & $\mathrm{R}$ & 5' AGGCAGGCTGMACGAAAGC \\
\hline Alpha tubulin & 2 & & $\mathrm{R}$ & 5' AACAGTTGGAGGCTGATAAT \\
\hline \multirow[t]{2}{*}{ Unifoliate } & Uni & AF010190 & $\mathrm{F}$ & 5' ТСТСТСТАСТGCACСАTCTC \\
\hline & & & $\mathrm{R}$ & 5' CTACATTCCCTCCCGTCCAT \\
\hline \multirow[t]{2}{*}{ Vicilin $\mathrm{J} / \mathrm{K}$} & $V c 2$ & X67429 & $\mathrm{F}$ & 5' GCTGCTACTCCAATCAAACCG \\
\hline & & & $\mathrm{R}$ & 5' CTTCAGTAACAGTTACTATCAC \\
\hline Vicilin & $V c 3$ & $\mathrm{X} 14076$ & $\mathrm{~F}$ & 5' ATGGCTGCTACTACAATG \\
\hline
\end{tabular}

zhttp://www.ncbi.nlm.nih.gov.

${ }^{\mathrm{y}}$ Cytosol-specific form.

xPlastid-specific form.

wNodule-specific form.

"After BLAST searching “short nearly identical sequences", sequences AF081457 (pectin methyl esterase) and X67425 (pectinesterase) proved to be more than $99 \%$ identical. The primers designed work for both genes.

"Mitochondria-specific (Mn-containing). 
Table 2. Annealing temperature, PCR product size, polymorphic enzyme and linkage map position of various STS primers in pea.

\begin{tabular}{|c|c|c|c|c|}
\hline $\begin{array}{l}\text { Gene } \\
\text { symbol }\end{array}$ & $\begin{array}{c}\text { Annealing } \\
\text { temp }{ }^{\circ} \mathrm{C}\end{array}$ & $\begin{array}{c}\text { Expected PCR } \\
\text { product size }\end{array}$ & Enzyme & $\begin{array}{c}\text { Linkage } \\
\text { group }\end{array}$ \\
\hline Aair & 60 & 2570 & Hinf I, Hae III & VII \\
\hline ApxI & 63 & 1700 & Alu I, Dde I & VII \\
\hline Apy & 62 & 2000 & Dde I & V \\
\hline bfruct & 62 & 480 & Mbo I & III \\
\hline CipPor & 65 & 1100 & Alu I & III \\
\hline Cop 1 & 60 & 2000 & Hae III & I \\
\hline CYP82AI & 60 & 1374 & --- & $V I$ \\
\hline Dimin & 62 & 1200 & Hae III & VII \\
\hline DRR49 & 60 & 600 & Hae III & VI \\
\hline Fbpase & 60 & 1700 & Sau 96 & V \\
\hline Ftase & 60 & 900 & Hae III & II \\
\hline$g d c T$ & 60 & 1360 & $\operatorname{Hinf} \mathrm{I}$ & IV \\
\hline Gib2BH & 60 & 1100 & --- & IV \\
\hline Gpic & 55 & $1500 / 1400$ & Hae III & VI \\
\hline Gsn 1 & 60 & 1350 & Ase I & VII \\
\hline Gsn2 & 60 & 1350 & Ase I & VI \\
\hline Gsp & 60 & 900 & Hae III & VI \\
\hline Hop 1 & 60 & 900 & Hae III & VI \\
\hline$h s f A$ & 62 & 514 & Tru9 I & III \\
\hline$i v d h$ & 60 & 1966 & $\operatorname{Hinf} \mathrm{I}$ & VII \\
\hline$L b$ & 60 & $1500 / 900$ & Dde I & I \\
\hline Sodmt & 60 & 1400 & Rsa I & III \\
\hline$P 393^{\mathrm{z}}$ & 60 & 516 & Hae III & IV \\
\hline$P 628^{\mathrm{z}}$ & 60 & 640 & Hinf I & IV \\
\hline Paal 1,2 & 60 & 2700 & Dde & V \\
\hline Pepcn & 60 & 3500 & $R s a \mathrm{I}$ & III \\
\hline phy & 60 & 1650 & Mbo I & II \\
\hline$R b$ & 60 & 3000 & Mbo I & III \\
\hline rcpmel & 65 & 620 & Alu I & V \\
\hline$R p l 22$ & 60 & 900 & $R s a \mathrm{I}$ & VI \\
\hline SAHH & 63 & 1500 & Hinf I & VII \\
\hline Ssym & 60 & 1850 & Hae III & IV \\
\hline TubAl & 63 & 1370 & $T a q \mathrm{I}$ & III \\
\hline Uni & 60 & 1250 & Rsa I & III \\
\hline$V c 2$ & 60 & 1612 & $R s a \mathrm{I}$ & V \\
\hline$V c 3$ & 58 & 2364 & Mbo I & III \\
\hline
\end{tabular}

${ }^{\mathrm{z}}$ Isolated and designed by Gilpin et al. (1997).

derived RILs constitute the population of 53 lines used to generate the consensus map (Weeden et al., 1998). The MN313 x JI1794 $\mathrm{F}_{2}$-derived RILs represent a related population of 51 lines that segregate for additional classical markers as well as for several genes influencing tolerance to common root rot (Przyborowski and Weeden, 2000). An initial screen for polymorphism among the amplified PCR products of the three parental lines was performed using the enzymes HinfI, HaeIII, RsaI, and DdeI. If these enzymes failed to reveal polymorphism, the following additional enzymes were included in the screen: $A l u \mathrm{I}, C f o \mathrm{I}, M b o \mathrm{I}, S a u 96 \mathrm{I}$, TaqI, and Tru9I. Once a polymorphism was observed between the parents, the RIL populations were scored, and the resulting segregation pattern was compared to those for previously mapped markers using the Quikmap EXCEL macro (N. Weeden and J. Barnard, unpublished). Confirmation that the sequences amplified and mapped were genuinely the gene sequences for which the prim- ers were designed was achieved by comparing the restriction fragment patterns observed to those predicted from analysis of the GenBank sequences imported into Webcutter 2.0 (http://www. firstmarket.com/cutter/cut2.html). For most of the genes mapped, the restriction fragment sizes obtained from several endonucleases were examined In three instances, where gene duplications may have occurred, it was not possible to determine which paralogue was polymorphic and the subject of mapping.

For analysis and mapping of STS markers in lentil we used an $\mathrm{F}_{2}$-derived $\mathrm{F}_{7}$ RIL population from the interspecific cross $L$. culinaris $\mathrm{x}$ L. ervoides. The $\mathrm{F}_{3}$ generation of this population was used by Weeden et al. (1992) in their comparison of linkage relationships between pea and lentil. Morphological characters were scored again on the $\mathrm{F}_{7}$ lines. The number of lines in the lentil RIL population (62) was sufficient that in many cases we could locate an STS marker on the map by comparing the $\mathrm{F}_{7}$ segregation data of the STS marker with that for the homozygous genotypes in the $\mathrm{F}_{3}$. In critical cases, the isozyme and DNA analysis on the $\mathrm{F}_{7}$ population was repeated.

\section{Results}

The 36 primer sequences that successfully amplified a product of the expected length in pea are shown in Table 1. In most cases the initial primers worked well; however, in several cases (e.g., CYP82A1, DRR49, Gib2BH, Gsp, Paal 1,2, Pepcn, Rb and Uni) a number of primers had to be tested before an appropriate combination, generating a strong amplification product, was obtained. In several cases (Gpic, Gsn, P393) secondary fragments were observed. For Gpic and P393 a single fragment predominated; however one other fragment displayed polymorphisms when cut with the endonuclease, and both could be mapped. For $G s n$, the single band observed on $2 \%(\mathrm{w} / \mathrm{v})$ agarose gels was found to consist of two fragments, both of which displayed polymorphism upon restriction. The annealing temperatures and amplicon sizes in pea for each primer pair are shown in Table 2.

Most primer pairs generated the same sized fragment in the three parental lines (JI1794, Slow, and MN313), at least at the resolving power of $2 \%(\mathrm{w} / \mathrm{v})$ agarose gels. The identity of amplified products was confirmed by restricting the fragment with one or more endonucleases (Fig. 1) and comparing the size of the resulting subfragments with those expected based on the sequence in GenBank. All amplified fragments, except for that amplified by $i v d h$ primers, gave the restriction patterns expected. The DNA fragment amplified by $i v d h$ primers gave several

Fig. 1. Restriction fragment sizes of PCR products from primers designed for alpha tubulin (TubA1) match those predicted for the GenBank accession: AluI $(169,231,238,327,327)$, Sau96I $(70,325,975)$, and TaqI $(264,482,575)$. The polymorphism for TaqI indicates that JI1794 fragment lacks one TaqI site shared by Slow and MN313 and has an additional site.

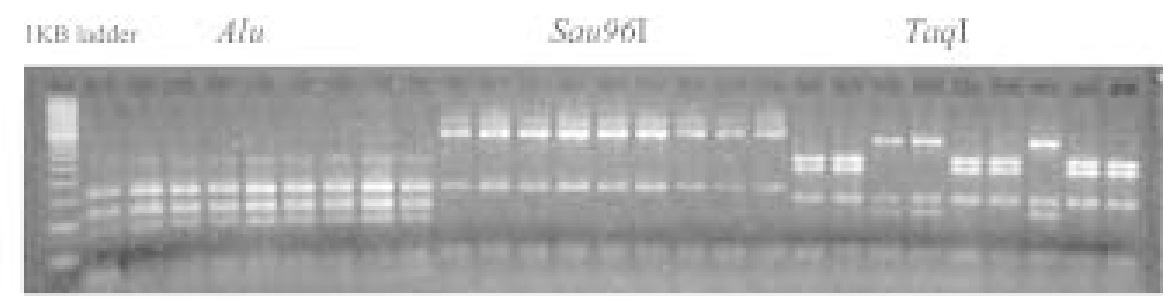

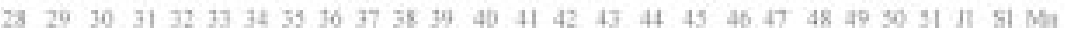



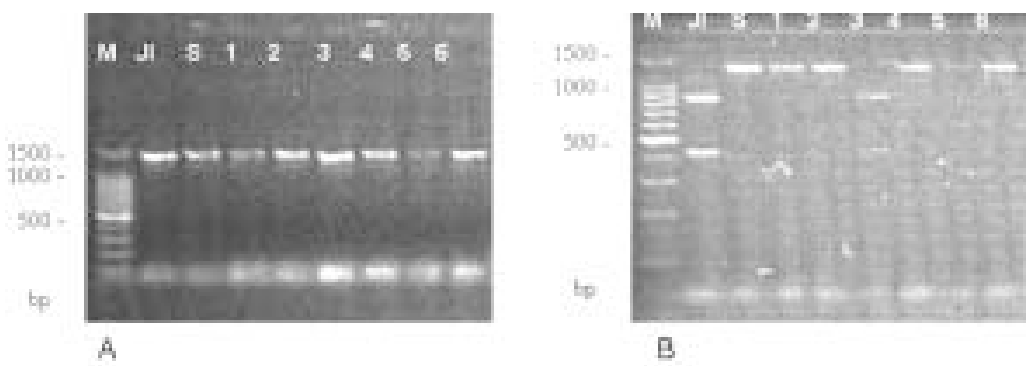

Fig. 2. Agarose gels of products from amplification of pea DNA using the SODmt primers. (A) Fragments observed directly after amplification. (B) Fragments observed after cutting amplified fragments with $R s a \mathrm{I} . \mathrm{M}=$ molecular weight marker, JI = JI1794 parental line, $\mathrm{S}=$ Slow parental line, $1-6=$ lines from the JI1794 x Slow RIL population.

additional fragments beyond those expected, suggesting the possibility that the primers have generated more than one overlapping fragment.

CAPS polymorphisms were observed for most of the STSPCR products, permitting the mapping of the respective genes in both pea RIL populations. Polymorphism in restriction sites was observed for nearly all fragments amplified from JI1794 DNA as compared to that of MN313 or Slow DNA. Insertion/deletion (indel) polymorphisms for bfruct and $G i b 2 B H$ were directly observable without restriction digestion. Only the actin STS was monomorphic for all of the restriction enzymes tested. The expected fragment size, restriction enzyme used for mapping and the linkage group on which a given STS locus was placed can be found in Table 2. Figure 2 displays the segregation of a polymorphism in pea for the sequence encoding Mn-containing superoxide dismutase. In this case, the sequence in one parent (JI1794) contained a $R s a$ I site, whereas the sequence in the other parent (Slow) was not cut by $R s a I$. Such a difference is easily resolved on $2 \%(\mathrm{w} / \mathrm{v})$ agarose gels.

The loci were widely scattered across the linkage map, with at least two genes mapping to each of the linkage groups (Fig. 3). None of the polymorphisms mapped outside the current ends of the linkage groups. The relative location of specific loci to anchor markers was the same in both RIL populations, although linkage intensities between loci occasionally varied.

Twenty of the primer pairs were tested using lentil DNA as a template. Thirteen of these generated amplification products of approximately the size expected (Table 3). Mapping of the Sodmt fragment in lentil placed it in a similar region of linkage group III as the Sodmt in pea (J.G. Walling and N.F. Weeden, unpublished). Hence, we assume that the fragment generated in lentil was de-

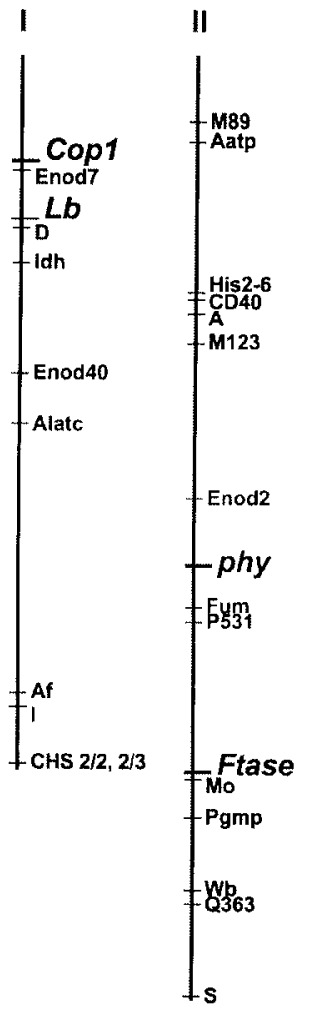

rived from a gene ortholo-gous to that which we mapped in pea. We also examined linkage relationships between two pairs of genes (Cop1/Lb and P363/P628) in lentil that displayed relatively close linkage in pea. In lentil, $C o p 1$ mapped within $5 \mathrm{cM}$ of $L b$ and $P 363$ mapped $\approx 10$ $\mathrm{cM}$ from $P 628$. These results clearly establish two areas of linkage conservation between pea and lentil. One of these had been identified previously (Weeden et al., 1992), but the P363/P628 region had not been tested before in lentil.

\section{Discussion}

The approach we have used to locate genes on the pea and lentil linkage maps appears to be a method applicable in most species in which segregating populations from wide crosses are available. The 36 genes listed in Table 2 represent about twothirds of the genes we have attempted to amplify using a CAPS analysis. Our success rate has been close to $100 \%$ when a sequence from pea is available. Design of primers from soybean or Arabidopsis sequences has proven more challenging, with a success rate of $<50 \%$. In certain cases appropriate primers have yet to be designed and the use of degenerate primers, as suggested by Brunel et al. (1999), might be a more satisfactory approach. In other cases (e.g., actin) the entire sequence within the gene appears to be highly conserved, and polymorphism could not be detected with a set of ten endonucleases. However, the large number of gene sequences, now or soon to be available, indicate that this approach will provide a sufficient number of markers to cover the genome at 5 to $10 \mathrm{cM}$ saturation.

Fig. 3. Linkage map of pea based on the mapping populations JI1794 $x$ Slow and MN313 x JI1794. The bar representing each linkage group extends to the most distal markers mapped on the respective group. Standard anchor markers are shown in small type. The STS markers listed in Table 2 are given in larger type, with their positions indicated by the heavier horizontal crossbars.

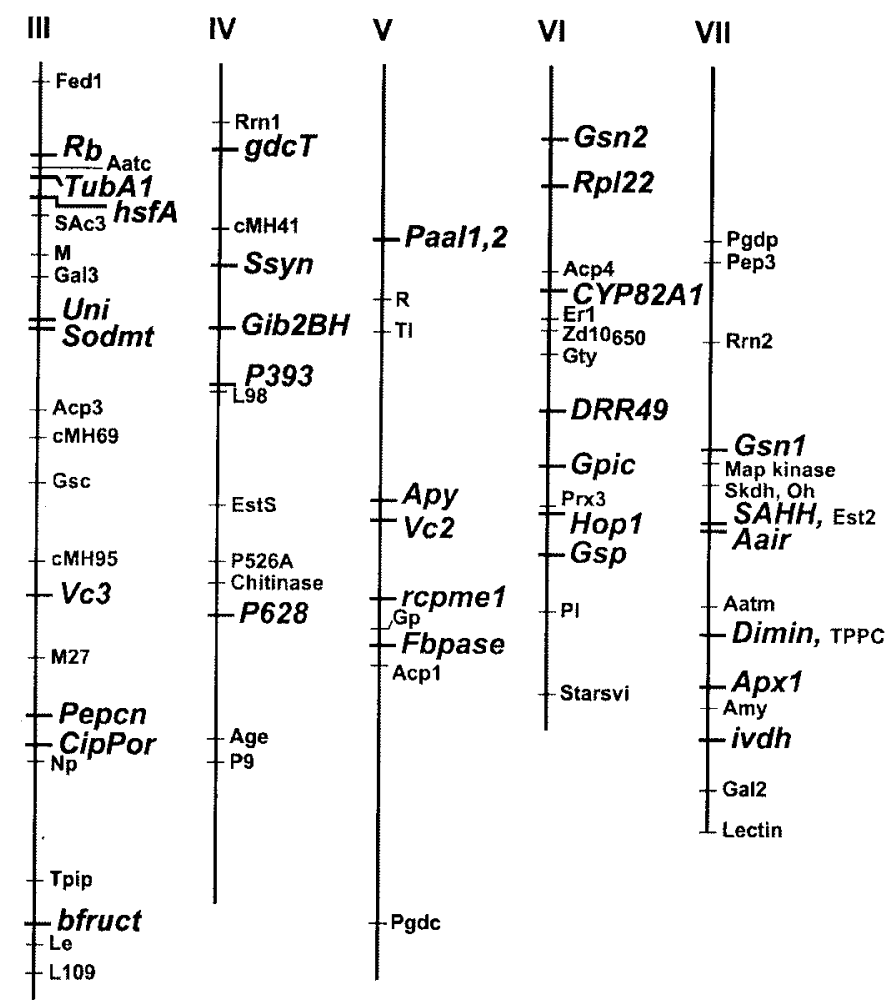


Table 3. STS primers that successfully amplified products in lentil.

\begin{tabular}{lcc}
\hline \hline $\begin{array}{l}\text { STS } \\
\text { primer }\end{array}$ & $\begin{array}{c}\text { Annealing } \\
\text { temp }\left({ }^{\circ} \mathrm{C}\right)\end{array}$ & $\begin{array}{c}\text { Fragment } \\
\text { size }\end{array}$ \\
\hline Cop & 60 & 1000 \\
P628 & 55 & $550+650$ \\
P393 & 55 & 550 \\
Fbpp & 55 & 1700 \\
Pepcn & 60 & 1300 \\
MnSOD & 55 & 1500 \\
Paal 1,2 & 55 & 1500 \\
Rcpme & 60 & 300 \\
Bfruct & 60 & 500 \\
Apxl & 60 & 800 \\
CipPor & 60 & $1000+1100$ \\
TubAl & 60 & $900+950+1500$ \\
Rpl22 & 60 & 900 \\
\hline
\end{tabular}

For most of the STS amplicons we were able to confirm that the correct fragment had been amplified. The restriction mapping of the product proved to be the most efficient method for confirmation. However, in several cases the position to which the fragment mapped on the pea linkage map also provided evidence. The two glutamine synthetase amplicons mapped to positions on linkage groups VI and VII that matched the positions of Gsnl and Gsn2 that had been previously mapped by RFLP analysis (Walker et al., 1995). Similarly, Gpic had been mapped to the same position on linkage group VI by isozyme analysis (Wolko and Weeden, 1990) and $R b$ is a well known morphological mutation mapping to the same position on linkage group III as the $A D P$ glucose pyrophosphorylase fragment (Rochat et al., 1995).

Several primer pairs developed from pea sequences did not generate a fragment of the expected size, or in some cases any fragment, when pea DNA was the template. In most of these cases the expected fragment size was $>2000 \mathrm{bp}$. Apparently our ability to amplify sequences larger than 2000 bp was not reliable even when amplification conditions were modified to optimize for long PCR and commercial polymerases such as Platinum Taq (Gibco) or Accutaq (Sigma) were used. We had hoped to reliably amplify fragments up to $5000 \mathrm{bp}$ in length as the opportunity for detection of polymorphism using restriction fragments would be increased. However, among the primer pairs we developed for fragments $>3000 \mathrm{bp}$, only those for Paal 1,2 consistently generated the desired fragment.

Two-thirds of the gene specific primers designed for pea amplified lentil sequences directly without further modification. Most of the primers were designed for conserved exon sequences, but in certain instances the conserved sequences did not yield primers with suitable properties and therefore primers that were optimal for pea were designed from less conserved sequences. Some of the sequences we amplified (vicilin $J / K, h s f A$ ) evolve relatively rapidly, and the priming sites may have undergone significant change since the divergence of pea and lentil. However other genes ( $g d c T, A p y)$ are relatively conserved but apparently also differed in the primer binding sites that were selected. In these cases, and in applications beyond borders of the tribe Viceae, primers with some degeneracy may work more efficiently. Alternatively, primers could be designed using the specific sequences for Medicago truncatula, Glycine max, or other appropriate taxa as more sequences become available. Several of the primer sets also amplified sequences in lupin (Przyborowski and Weeden, unpublished), suggesting that given an appropriate mapping population in this crop, a test for linkage conservation between pea and lupin would be relatively easy.

Our approach appears to be more efficient at finding polymorphic markers than that used by Gilpin et al. (1997). Of the 18 STSs for which they report primers, nearly half did not show polymorphism or were not appropriate (generated multiple fragments) for comparative mapping. The two loci we used (P393 and P628) are excellent markers, as are two others, $L 109$ and $Q 363$ which were not previously mentioned above. The primers reported by Schneider et al. (1999) have not worked particularly well in pea. Presumably the homologous priming sequences in pea contain too many nucleotide substitutions relative to gene sequences from the Brassicaceae to permit direct application of the primer sequences given by Schneider et al. (1999). We conclude that STS primer sets ideally should be developed from gene sequences obtained within the same family of flowering plants. In addition, the level of polymorphism observed using this approach has been somewhat disappointing in narrower crosses (within cultivated germplasm). The line JI1794 is an accession of Pisum sativum ssp. elatius and exhibits considerable genetic divergence from cultivated types. When different pea cultivars were tested for polymorphism using the STS markers and ten restriction enzymes, we often were unable to observe polymorphism. Thus, the CAPS approach does not appear to be highly applicable to breeding programs. We did not sequence the products from the various breeding lines we tested, and it is possible that there may be substantial sequence polymorphism such as single nucleotide polymorphisms (SNPs) which were not detected by the set of restriction enzymes we used.

With a set of STS markers, it should be possible to rapidly examine the changes that have occurred in the arrangement of genes in related genera. The approach is simple, requiring only PCR and agarose gel electrophoresis capabilities. Radiochemical labeling or denaturing polyacrylamide gels are not required, although considerably more genetic variation could be revealed using such tools. As described above, the technique can be applied in many laboratories with modest equipment and financial resources. Hence, the approach should be useful for the comparison of linkage maps in many minor legume crops such as grass-pea, lentil, field bean, chickpea, red clover, white clover, sweet-clover, bird's foot trefoil, tepary bean, mung bean, cowpea, winged bean, pigeon pea, lablab, indigo, lupin, sainfoin, yam bean, tamarind, bambara goundnut, derris, and guar.

\section{Literature Cited}

Boutin, S.R., N.D. Young, T.C. Olson, Z.H. Yu, R.C. Shoemaker, and C.E. Vallejos. 1995. Genome conservation among three legume genera detected with DNA markers. Genome 38:928-937.

Brunel, D., N. Froger, and G. Pelletier. 1999. Development of amplified consensus genetic markers (ACGM) in Brassica napus from Arabidopsis thaliana sequences of known biological function. Genome 42:387402.

Dirlewanger, E., P.G. Issac, S. Ranade, M. Belajouza, R. Cousin, and D. de Vienne. 1994. Restriction fragment length polymorphism analysis of loci associated with disease resistance genes and developmental traits in Pisum sativum L. Theor. Appl. Genet. 88:17-27.

Ellis, T.H.N., L. Turner, R.P. Hellens, D. Lee, C.L. Harker, C. Enard, C. Domoney, and D.R. Davies. 1992. Linkage maps in pea. Genetics 130:649-663.

Gilpin, B.J., J.A. McCallum, T.J.Frew, and G.M. Timmerman-Vaughan. 1997. A linkage map of the pea (Pisum sativum L.) genome containing cloned sequences of known function and expressed sequence tags (ESTs). Theor. Appl. Genet. 95:1289-1299. 
Irzykowska, L., B. Wolko, and W.K. Swiecicki. 2001. The genetic linkage maps of pea (Pisum sativum L.) based on molecular, biochemical and morphological markers. Pisum Genetics 33:13-18.

Jarvis, P.C. Lister, V. Szabo, C. Dean, A. Konieczny, and F.M. Ausubel. 1994. Integration of CAPS markers into the RFLP map generated using recombinant inbred lines of Arabidopsis thaliana. Plant Mol. Biol. 24:685-687.

Laucou, V.K. Haurogne, N. Ellis, and C. Rameau. 1998. Genetic mapping in pea. I. RAPD-based linkage map of Pisum sativum. Theor. Appl. Genet. 97:905-915.

Lee, J.M., D. Grant, C.E. Vallejos, and R.C. Shoemaker. 2001. Genome organization in dicots. II. Arabidopsis as a 'bridging species' to resolve genome evolution events among legumes. Theor. Appl. Genet. 103:765773.

McCallum, J., G. Timmerman-Vaughan, T.J. Frew, and A.C. Russell. 1997. Biochemical and genetic linkage analysis of green seed color in field pea (Pisum sativum L.). J. Amer. Soc. Hort. Sci. 122:218-225.

Olson, M., L. Hood, C. Cantor, and D. Botstein. 1989. A common language for physical mapping of the human genome. Science 245:14341435.

Przyborowski, J., and N.F. Weeden. 2000. The position of locus $A$ on the consensus map. Pisum Genetics 32:60-61.

Rochat, C., S. Wuilleme, J.-P. Boutin, and C.L. Hedley. 1995. A mutation at the rb gene, lowering ADPGPPase activity, affects storage product metabolism of pea seed coats. J. Exptl. Bot. 46:415-421.

Schneider, K., D.C. Borchardt, R. Schäfer-Pregl, N. Nagl, C. Glass, A. Jeppsson, C. Gebhardt, and F. Salamini. 1999. PCR-based cloning and segregation analysis of functional gene homologues in Beta vulgaris. Mol. Gen. Genet. 262:515-524.

Simon, C.J. and F.J. Muehlbauer. 1997. Construction of a chickpea linkage map and its comparison with maps of pea and lentil. J. Hered. 88:115-119.

Torres, A.M., N.F. Weeden, and A. Martin. 1993. Linkage among isozyme, RFLP and RAPD markers in Vicia faba. Theor. Appl. Genet. 85:937-945.

Walker, E.L., N.F. Weeden, C.B. Taylor, P. Green, and G.M. Coruzzi. 1995. Molecular evolution of duplicate copies of genes encoding cytosolic glutamine synthetase in Pisum sativum. Plant Mol. Biol. 29:1111-1125.

Weeden, N.F., T.H.N. Ellis, G.M. Timmerman-Vaughan, W.K. Swiecicki, S.M. Rozov, and V.A. Berdnikov. 1998. A consensus linkage map for Pisum sativum. Pisum Genet. 30:1-4.

Weeden, N.F., F.J. Muehlbauer, and G. Ladizinsky. 1992. Extensive conservation of linkage relationships exists between pea and lentil genetic maps. J. Hered. 83:123-129.

Wolko, B. and N.F. Weeden. 1990. Pisum Nwsltt. 22:71-72. 